\title{
Genetic Variance Component and Heritability Estimates of Freedom from Weevil Injury to Sweetpotato
}

\author{
P.G. Thompson and John C. Schneider \\ Departments of Horticulture and Entomology, Mississippi State University, Mississippi State, MS 39762
}

Boyett Graves

Mississippi Agricultural and Forestry Experiment Station, 478 Highway 15, Beaumont, MS 39423

Additional index words. Ipomoea batatas, Cylas formicarius elegantulus, polyploid, half-sib family, parent-offspring regression, genetic correlation

\begin{abstract}
Narrow-sense heritability for component traits of freedom from weevil injury and yield of sweetpotato were estimated by parent-offspring regression and variance component analysis. Heritability estimates by variance component analysis based on half-sib families for percent and number of uninjured roots were 0.25 and 0.83 , respectively. Individual plant heritability estimates for uninjured root percent and number were 0.03 and 0.13 , respectively. Heritability estimates by parent-offspring regression for uninjured root percent and number were 0.35 and 0.52 , respectively. Genetic variance was mostly additive for all traits except stem diameter. Genetic correlations between total root number, uninjured root number, and percent uninjured roots ranged from 0.66 to 0.87 , indicating that selection for uninjured root number should most effectively increase uninjured root number and percent, as well as total root numbers. Predicted gains in uninjured root percent and number were $8.8 \%$ and 0.87 in the progeny derived from intermating the highest four out of 19 families for uninjured root number. The 0.87 gain in uninjured root number equals a $24 \%$ increase in one breeding cycle.
\end{abstract}

The sweetpotato weevil is the most destructive worldwide pest of sweetpotato (Chalfant et al., 1990). Adult weevils feed on above- and below-ground plant parts and oviposit in storage roots. Larvae feed and develop inside the root and render it inedible. Insecticidal control is difficult due to inaccessibility of the immature stages of the insect. In addition, the weevil's host range, which includes sweetpotatoes and related Ipomoea spp., and its movement in commerce contribute to the difficulty of control. An integrated pest-management program would be the most effective control for the weevil. One essential component of the program that has not been advanced as far as other components is host-plant resistance.

Low levels of weevil resistance have been found and levels increased in breeding programs of short duration (Hahn and Leuschner, 1981; Mullen et al., 1985). There is a need to determine if breeding can further increase weevil resistance levels at a reasonable progress rate. Primarily additive genetic variance contributes to gain from selection following intermating selected parents. Therefore, an estimate of narrow-sense heritability, which is the ratio of additive genetic variance to phenotypic variance, is needed to estimate progress rate in increasing sweetpotato weevil resistance. Estimates of genetic correlations between component traits of weevil resistance and yield are also needed to determine if yield and weevil resistance can be increased simultaneously.

The objectives of this study were to estimate narrow-sense heritabilities $\left(\mathrm{h}^{2}\right)$ and genetic correlations between component traits of weevil resistance and yield in a sweetpotato breeding population.

Received for publication 7 Sept. 1993. Accepted for publication 6 Dec. 1993. Article no. J-8366 of the Mississippi Agricultural and Forestry Experiment Station. We gratefully acknowledge the International Potato Center for its financial support and A. Jones, P.D. Dukes, J.M. Schalk, and M.A. Mullen for plant materials and information. The cost of publishing this paper was defrayed in part by the payment of page charges. Under postal regulations, this paper therefore must be hereby marked advertisement solely to indicate this fact.
Materials and Methods

Plant materials. Seeds of half-sib families were produced by open-pollination of 19 parental clones. Parents included clones originating in four U.S. breeding programs. Entries with the highest resistance levels in evaluations by Mullen et al. (1985), such as 'Resisto' and 'Regal', were included as parents or as firstgeneration breeding lines. Parental clones, polycross progenies, and three controls were evaluated in 1990 and 1991. The controls and their previously determined resistance levels (Mullen et al., 1985) were 'Centennial' (susceptible), 'Jewel' (intermediate), and 'Regal' (moderate).

Insects. During the winter before each evaluation, weevils were collected from storage roots infested the previous season in producer's fields at four to six Mississippi locations. They were cultured on storage roots in 1.1-liter glass jars. Wild weevils were increased separately by location of origin over three generations, after which 20 males and 20 females from different locations were placed in each of a series of jars to oviposit in roots for a 7-day period. Weevils eclosed from those roots were used for field infestation.

Resistance evaluation. Field evaluations were conducted at the South Mississippi Branch Experiment Station in Beaumont, Miss. Beaumont is in a weevil-infested area, but naturally occurring weevil numbers were low because sweetpotatoes had not been grown for many years. Weevil injury in both years of evaluation appeared to be nearly exclusively from applied weevils since few weevils were caught in pheromone traps before releases were made at the beginning of sweetpotato-storage root enlargement.

Progeny plants were started from seed in 1990 and transplanted to field plots. Vegetative cuttings were maintained in a greenhouse to reproduce the half-sib progeny families for the 1991 planting. Parents and control plants were propagated by bedding storage roots. A randomized complete-block design was used, with five plant plots of each entry replicated seven times. Plants were spaced $36 \mathrm{~cm}$ apart in rows $1 \mathrm{~m}$ apart.

One female and one male weevil were applied to the crown of 
each plant 73 and 99 days after transplanting (DAT) in 1990 and 1991, respectively. Plants with storage roots attached were harvested 143 and 129 DAT in 1990 and 1991, respectively. Evaluations were begun immediately after harvest in 1990. Due to limited time between weevil application and harvest in 1991, plants with roots attached were held in a greenhouse for 67 days after harvest to allow time for weevil eclosure.

Measurements made on individual plants in 1990 were stem diameter, depth from soil line to first storage root attachment, presence or absence of stem injury by weevils, and number and weight of weevil-injured and uninjured roots. Stem diameter and depth from the soil line to first storage root attachment were measured to test for a relationship between those traits and number of weevil-injured roots. Number and weight of weevil-injured roots were regressed on stem diameter and depth of storage root attachment. The regression coefficients between injured roots and depth of storage root attachment were nonsignificant $(P<0.05)$; consequently, depth of storage root attachment was not measured in 1991. Heritability estimates were calculated with the first-year data for an indication of the amount of information from the various measurements. Estimates were similar between number and weight of uninjured roots, 0.47 and 0.46 , respectively. Therefore, injured and uninjured root weights were not taken in 1991.

Genetic estimates. Heritabilities were estimated by half-sib family analysis and parent-offspring regression. Half-sib family analyses were performed with plot mean values and also with individual plant data. The genetic model assumed linkage equilibrium, no epistasis, no selection of parental plants, and hexasomic inheritance with random chromosomal segregation. Under those assumptions, $\sigma_{\mathrm{f}}^{2}=\mathrm{COVHS}=1 / 4 \sigma_{\mathrm{A}}^{2}+1 / 25 \sigma_{\mathrm{D}}^{2}$, where $\sigma_{\mathrm{f}}^{2}$ was the estimated variance due to genetic differences among half-sib families, and $\sigma_{\mathrm{A}}{ }^{2}$ and $\sigma_{\mathrm{D}}{ }^{2}$ were the additive and digenic components of genetic variance, respectively (Kempthorne, 1957).

Total genetic variance $\left(\sigma_{\mathrm{G}}{ }^{2}\right)$ was estimated from parental plant analysis, by $\sigma_{\mathrm{P}}{ }^{2}=\sigma_{\mathrm{A}}{ }^{2}+{\sigma_{\mathrm{D}}}^{2}+\sigma_{\mathrm{T}}{ }^{2}+{\sigma_{\mathrm{Q}}}^{2}+{\sigma_{\mathrm{L}}}^{2}+{\sigma_{\mathrm{H}}}^{2}$, where $\sigma_{\mathrm{P}}{ }^{2}$ was variance due to genetic differences among parental plants and $\sigma_{\mathrm{T}}{ }^{2}$, $\sigma_{\mathrm{Q}}^{2}, \sigma_{\mathrm{L}}^{2}$, and $\sigma_{\mathrm{H}}^{2}$ were the trigenic, quadragenic, pentagenic, and hexagenic components of genetic variance, respectively.

Additive genetic variance was estimated as $4 \sigma_{\mathrm{f}}^{2}$, which would be inflated by the $1 / 25 \sigma_{\mathrm{D}}^{2}$ contained in $\sigma_{\mathrm{f}}^{2}$. The presence of nonadditive genetic variance $\left(\sigma_{\mathrm{NA}}{ }^{2}\right)$ was estimated by the difference $\sigma_{\mathrm{P}}{ }^{2}-4 \sigma_{\mathrm{f}}^{2}$, which contained $21 / 25 \sigma_{\mathrm{D}}{ }^{2}+\sigma_{\mathrm{T}}{ }^{2}+\sigma_{\mathrm{Q}}{ }^{2}+\sigma_{\mathrm{L}}{ }^{2}+\sigma_{\mathrm{H}}{ }^{2}$. That estimate would be an indication of the amount of inflation in $\sigma_{\mathrm{A}}{ }^{2}$ due to the $1 / 25 \sigma_{\mathrm{D}}{ }^{2}$ contained in $\sigma_{\mathrm{f}}^{2}$, and also the magnitude of variance from interactions of genes at a locus.

The formula for narrow-sense heritability of half-sib families was $h^{2}=4 \sigma_{\mathrm{f}}^{2} / \sigma_{\mathrm{f}}^{2}+\sigma_{\mathrm{fy}}{ }^{2} / \mathrm{y}+\sigma_{\mathrm{e}}{ }^{2} /(\mathrm{ry})$, where $\mathrm{y}, \mathrm{e}$, and $\mathrm{r}=$ years, error, and replication, respectively, and for individual plants: $h^{2}=4 \sigma_{f}^{2} /$ $\sigma_{\mathrm{f}}^{2}+\sigma_{\mathrm{fy}}{ }^{2} / \mathrm{y}+\sigma_{\mathrm{t}}^{2}+\sigma_{\mathrm{w}}{ }^{2}$, where $\sigma_{\mathrm{t}}^{2}$ and $\sigma_{\mathrm{w}}{ }^{2}$ equal the variance among plots within a block and the variance among plants within plots, respectively.

To derive $\mathrm{h}^{2}$ estimates by parent-offspring regression with low genotype $\times$ environment interaction, offspring data from year 1 were regressed on parental data from year 2 , and offspring year 2 on parental year 1. Regression coefficients were averaged and multiplied by 2 for the heritability estimate.

Genetic correlations of traits $\mathrm{X}$ and $\mathrm{Y}$ were estimated as follows: $\mathrm{r}_{\mathrm{Gxy}}=\sigma_{\mathrm{Axy}} /\left(\sigma_{\mathrm{Ax}}{ }^{2} \cdot \sigma_{\mathrm{Ay}}{ }^{2}\right)$, where $\sigma_{\mathrm{Axy}}$ was the additive covariance estimate and $\sigma_{\mathrm{Ax}}{ }^{2}$ and $\sigma_{\mathrm{Ay}}{ }^{2}$ were the additive variance component estimates.

Table 1. Uninjured and total roots produced by families evaluated for freedom from sweetpotato weevil injury.

\begin{tabular}{|c|c|c|c|c|c|c|c|c|c|}
\hline \multirow[b]{2}{*}{ Family $^{z}$} & \multicolumn{3}{|c|}{ Uninjured root $\%$} & \multicolumn{3}{|c|}{$\begin{array}{l}\text { Uninjured root no. } \\
\text { per plant }\end{array}$} & \multicolumn{3}{|c|}{$\begin{array}{l}\text { Total root no. } \\
\text { per plant }\end{array}$} \\
\hline & 1990 & 1991 & Mean & 1990 & 1991 & Mean & 1990 & 1991 & Mean \\
\hline NC718 & 81 & 65 & 73 & 3.8 & 4.1 & 4.0 & 4.8 & 6.4 & $\overline{5.6}$ \\
\hline W244 & 71 & 71 & 71 & 2.9 & 4.8 & 3.8 & 4.2 & 6.9 & 5.5 \\
\hline W263 & 70 & 71 & 71 & 3.1 & 4.0 & 3.5 & 4.1 & 6.2 & 5.1 \\
\hline Resisto & 78 & 64 & 71 & 4.4 & 5.0 & 4.7 & 5.8 & 7.9 & 6.8 \\
\hline MS211 & 68 & 72 & 70 & 3.1 & 5.8 & 4.5 & 4.6 & 8.1 & 6.3 \\
\hline W250 & 72 & 66 & 69 & 4.0 & 4.7 & 4.3 & 5.1 & 7.9 & 6.5 \\
\hline MS114 & 73 & 62 & 68 & 3.0 & 3.6 & 3.3 & 3.8 & 6.0 & 4.9 \\
\hline MS1631 & 68 & 63 & 66 & 3.6 & 5.4 & 4.5 & 4.5 & 8.4 & 6.5 \\
\hline $\operatorname{Regal}^{y}$ & 63 & 68 & 66 & 4.6 & 4.4 & 4.5 & 6.7 & 7.0 & 6.9 \\
\hline MS741 & 71 & 60 & 65 & 3.5 & 4.3 & 3.9 & 5.0 & 7.1 & 6.0 \\
\hline W115 & 73 & 52 & 63 & 2.2 & 3.4 & 2.8 & 2.9 & 6.5 & 4.7 \\
\hline Excel & 66 & 56 & 61 & 3.1 & 4.2 & 3.6 & 4.6 & 7.6 & 6.1 \\
\hline Beauregard & 63 & 60 & 61 & 3.1 & 3.4 & 3.3 & 5.0 & 5.3 & 5.1 \\
\hline MS2137 & 59 & 64 & 61 & 3.1 & 5.0 & 4.1 & 5.6 & 7.7 & 6.7 \\
\hline MS105 & 67 & 54 & 61 & 3.3 & 3.4 & 3.4 & 4.8 & 6.8 & 5.8 \\
\hline Jewel $^{\mathrm{y}}$ & 63 & 59 & 61 & 3.4 & 4.4 & 3.9 & 6.1 & 6.6 & 6.4 \\
\hline US873 & 63 & 58 & 60 & 3.5 & 3.5 & 3.5 & 5.1 & 6.5 & 5.8 \\
\hline NC902 & 74 & 44 & 59 & 2.9 & 3.1 & 3.0 & 3.9 & 6.4 & 5.2 \\
\hline MS1012 & 72 & 45 & 58 & 2.6 & 3.3 & 3.0 & 4.2 & 6.7 & 5.5 \\
\hline Centennial $^{\mathrm{y}}$ & 42 & 66 & 54 & 3.0 & 4.8 & 3.9 & 6.9 & 7.6 & 7.2 \\
\hline MS121 & 44 & 58 & 51 & 2.2 & 4.0 & 3.1 & 5.9 & 6.0 & 6.0 \\
\hline MS49 & 45 & 45 & 45 & 1.6 & 3.1 & 2.4 & 4.2 & 6.2 & 5.2 \\
\hline LSD $(0.05)$ & 26 & 15 & 22 & 1.7 & 1.8 & 1.7 & 1.8 & 2.2 & 1.9 \\
\hline
\end{tabular}

${ }^{\mathrm{z}}$ Family designation is female parent.

${ }^{\mathrm{y}}$ Control clone (not a family). 
Table 2. Genetic variance component estimates +SE of traits evaluated for freedom from sweetpotato weevil injury and yield.

\begin{tabular}{|c|c|c|c|c|c|}
\hline Trait & $\sigma_{\mathrm{A}} 2$ & $\sigma_{\mathrm{A} \cdot \mathrm{E}} 2$ & $\sigma_{\mathrm{G}} 2$ & $\sigma_{\mathrm{G} \cdot \mathrm{E}} 2$ & $\sigma_{\mathrm{NA}}^{2}$ \\
\hline \multirow{2}{*}{$\begin{array}{l}\text { Stem } \\
\text { diameter }\end{array}$} & 1.4154 & 0.0778 & 2.6038 & 0.4661 & 1.1884 \\
\hline & \pm 0.12804 & \pm 0.0148 & \pm 1.1106 & \pm 0.1220 & \\
\hline \multirow{2}{*}{$\begin{array}{l}\text { Yield } \\
\text { (g per plot) }\end{array}$} & -82.7344 & 45.2340 & 130.0833 & 296.0664 & \\
\hline & \pm 578.4303 & \pm 81.9311 & \pm 297.1936 & \pm 415.1732 & \\
\hline \multirow{2}{*}{$\begin{array}{l}\text { Root size } \\
\quad \text { (g per root) }\end{array}$} & 40.0120 & 344.7613 & 492.0229 & 418.2929 & \\
\hline & \pm 152.7842 & \pm 1003.9960 & \pm 2013.7147 & \pm 2313.8021 & \\
\hline \multirow[t]{2}{*}{ Root no. } & 0.5943 & 0.0351 & 0.6611 & 1.5472 & 0.0668 \\
\hline & \pm 0.0830 & \pm 0.0297 & \pm 0.4430 & \pm 0.4863 & \\
\hline \multirow{2}{*}{$\begin{array}{r}\text { Uninjured } \\
\text { root no. }\end{array}$} & 1.0604 & 0.0706 & 1.1434 & 0.8904 & 0.0830 \\
\hline & \pm 0.0765 & \pm 0.0408 & \pm 0.4958 & \pm 0.2029 & \\
\hline \multirow[t]{2}{*}{ Uninjured root \% } & 3.3688 & 13.8164 & 3.4791 & 0.9605 & 0.1103 \\
\hline & \pm 0.8640 & \pm 3.8351 & \pm 1.7932 & \pm 0.0376 & \\
\hline
\end{tabular}

\section{Results}

Mean uninjured root percents and numbers ranged from $45 \%$ to $73 \%$ and from 2.4 to 4.7 (Table 1). Agreement in ranking among families for uninjured root number and percent was close with a few exceptions. Families from parents NC718, W244, and W263 were the highest for percent of uninjured roots, but uninjured numbers were lower than other families such as 'Resisto' and MS211. MS114 also ranked higher for uninjured percent than for number. Those families, of course, produced low root numbers with few injured roots so that percent injury was low, but likewise uninjured root numbers were low compared to the families of 'Resisto' and MS211.

Ranking of control cultivars for percent uninjured roots was as expected with 'Regal' being highest, 'Jewel' intermediate, and 'Centennial' most susceptible to weevil injury. However, for uninjured root number 'Jewel' and 'Centennial' were equal.

Additive genetic variance estimates were high and additive $\times$ environment interactions $\left(\sigma_{\mathrm{A} \cdot \mathrm{E}}{ }^{2}\right)$ were low for stem diameter, number of uninjured roots, and total root number (Table 2). For stem diameter the additive estimate was 11 times its SE. Uninjured root number and total root number additive genetic variance estimates were also much larger than their sEs. The additive variance estimate for percent uninjured roots was less than four times its SE.

Additive $\times$ environment interaction estimates were extremely low for stem diameter, uninjured root number, and total root number. The additive variance estimates were 18,15 , and 17 times $\sigma_{\mathrm{AE}}{ }^{2}$ for those traits, respectively. Percent uninjured root number had an additive estimate 0.24 times $\sigma_{A \mathrm{E}}{ }^{2}$.

Additive and total genetic variance estimates for components of yield involving storage root weight, yield and root size, were less than their ses (Table 2). Therefore, increased yield in this population is dependent on selection for increased root numbers.

The difference $\sigma_{\mathrm{P}}^{2}-4 \sigma_{\mathrm{f}}^{2}$ was high enough for stem diameter to indicate the presence of nonadditive genetic variance; therefore, the $\sigma_{\mathrm{A}}{ }^{2}$ estimate for that trait was possibly biased because of the 1/ $25 \sigma_{\mathrm{D}}^{2}$ contained in $\sigma_{\mathrm{f}}^{2}$. The magnitude of the bias would be low. If the entire $\sigma_{\mathrm{P}}{ }^{2}-4 \sigma_{\mathrm{f}}{ }^{2}$ were $\sigma_{\mathrm{D}}{ }^{2}$, then $1 / 25(1.884)=0.0753$ and the $\sigma_{\mathrm{A}}^{2}$ estimate would be reduced from 1.4154 to 1.3401 , a $5 \%$ reduction. The $\sigma_{\mathrm{P}}^{2}-4 \sigma_{\mathrm{f}}^{2}$ estimates were extremely low for all remaining traits, indicating that nonadditive variance will have little effect on gain from selection for those traits.

Half-sib family heritabilities merit discussion because the heritability estimates from half-sib family means were higher than those from individual plants for all traits (Table 3). Heritabilities of percent uninjured roots were 0.25 and 0.35 by variance component and parent-offspring regression analyses, respectively. Uninjured root number heritability estimates were 0.83 and 0.52 by variance component and regression analyses, respectively. The higher heritability for uninjured root number than for percent uninjured roots indicates that genetic gain in resistance should be greater by selecting for uninjured root number rather than percentage.

The heritability estimate for total root number was high $(0.70)$ by variance component analysis, but lower $(0.22)$ by parentoffspring regression. Yield and root size had $\mathrm{h}^{2}$ estimates lower than their ses by variance component and regression analyses.

Genetic correlations among root number and percent and number of weevil-uninjured roots were relatively high (Table 4). Stem diameter was negatively correlated with number and percent of uninjured roots. The correlations were low, -0.13 and -0.14 for number and percentage, respectively, but larger than their SEs. The low values suggest that indirect selection for smaller stem diameter to increase uninjured roots would not be effective because of slow

Table 3. Narrow-sense heritability estimates \pm SE of traits evaluated for freedom from sweetpotato weevil injury.

\begin{tabular}{lcccr}
\hline \hline & Stem & $\begin{array}{c}\text { Root } \\
\text { no. }\end{array}$ & $\begin{array}{c}\text { Uninjured } \\
\text { root } \\
\text { no. }\end{array}$ & $\begin{array}{c}\text { Uninjured } \\
\text { root } \\
\%\end{array}$ \\
\hline Method & diam & 0.7011 & 0.8267 & 0.2513 \\
plot mean & \pm 0.0817 & \pm 0.0980 & \pm 0.0710 & \pm 0.0162 \\
Individual plant & 0.1456 & 0.0638 & 0.1311 & 0.0293 \\
& \pm 0.0132 & \pm 0.0089 & \pm 0.0098 & \pm 0.0018 \\
Parent-offspring & 0.4126 & 0.2238 & 0.5183 & 0.3522 \\
regression & \pm 0.1801 & \pm 0.1781 & \pm 0.1894 & \pm 0.2161 \\
\hline
\end{tabular}

Table 4. Genetic correlations \pm SE of traits evaluated for freedom from sweetpotato weevil injury.

\begin{tabular}{lccc}
\hline \hline & & Uninjured \\
& Root & root & $\begin{array}{c}\text { Uninjured } \\
\text { root } \\
\%\end{array}$ \\
& no. & no. & -0.1437 \\
\hline Stem diameter & 0.0108 & -0.1277 & \pm 0.0749 \\
& \pm 0.1126 & \pm 0.0868 & 0.8723 \\
Root no. & & 0.6593 & \pm 0.0227 \\
& & \pm 0.0619 & 0.7916 \\
Uninjured & & & \pm 0.0278 \\
root no. & & &
\end{tabular}


rate of gain in uninjured roots.

No injury to above-ground plant parts was observed during these evaluations. Lack of stem injury was possibly due to an abundance of soil cracks at time of weevil release, allowing direct entrance to storage roots.

\section{Discussion}

The higher heritability estimates for half-sib families than for individual plants suggests that the selection unit for increased weevil resistance should be half-sib families. The use of all plants in a seedling family for subsequent intercrossing and selection would, however, be impractical. Therefore, selection of the highest performing plants from the top performing families would be an effective method to reduce numbers and still practice family selection.

The optimum trait to select for increased weevil resistance would seem to be percent of uninjured roots because the effect of differences in root number among genotypes would be removed from the resistance measurement. However, examination of these results indicates that number of uninjured roots should be considered as the trait for selection. Heritability was higher and genotype $x$ environment interaction lower for uninjured root number than percent.

To compare rates of gain from selection for each of the characters, the formula for a correlated response in trait $\mathrm{Y}$ when selection is practiced for trait $\mathrm{X}$ can be used: $\mathrm{CR}_{\mathrm{Y}}=\mathrm{i} \mathrm{h}_{\mathrm{x}} \mathrm{h}_{\mathrm{y}} \mathrm{r}_{\mathrm{a}} \sigma_{\mathrm{PY}}$, where $\mathrm{i}=$ selection intensity, $\mathrm{r}_{\mathrm{A}}=$ genetic correlation between traits $\mathrm{X}$ and $\mathrm{Y}$, and $\sigma_{\mathrm{PY}}=$ phenotypic standard deviation of trait $\mathrm{Y}$ (Falconer, 1989). The response to direct selection for trait $X$ is given by: $G=$ i $\sigma_{p} h^{2}$. Both formulas give the gain expected in the population mean of the progeny derived from intermating the parents included in the specified selection intensity. Consider selection for increased uninjured root number by selecting and intermating the highest four families out of 19 . Using variance component $h^{2}$ estimates, predicted progeny gains in mean uninjured root number and percent are 0.87 and $8.8 \%$. Selection for percent of uninjured roots results in predicted gains of 0.63 uninjured roots and $5 \%$ uninjured. Predicted gains are, therefore, higher for both traits with direct selection for increased uninjured root number rather than percent uninjured. The increased gain in percent uninjured roots from indirect selection over direct selection is due to the high genetic correlation between traits and to higher $h^{2}$ and lower $\sigma_{\mathrm{A} \cdot \mathrm{E}}{ }^{2}$ for uninjured root number than for percent uninjured. In addition to increased injury-free roots, selection for uninjured root number will result in a total root number gain of 0.43 roots per plant, which equals a $7.4 \%$ gain in root number.

The expected gain in number of uninjured roots is high. The 0.87 gain is an increase of $24 \%$ in one selection cycle, since the mean number of uninjured roots per plant was 3.6 in the measured population. This indicates that progress in increasing injury-free roots should be fairly rapid. In quantifying actual progress rate, however, the low level of weevil numbers used in these evaluations must be considered. Weevil numbers should be increased to simulate high infestation levels found in many areas where weevils occur. Weevil numbers will be increased in our evaluations as resistance levels are increased.

\section{Literature Cited}

Chalfant, R.B., R.K. Jansson, D.R. Seal, and J.M. Schalk. 1990. Ecology and management of sweetpotato insects. Annu. Rev. Entomol. 35:157-180.

Falconer, D.S. 1989. Introduction to quantitative genetics. Longman Sci. and Tech., London and New York.

Hahn, S.K. and K. Leuschner. 1981. Resistance of sweetpotato cultivars to African sweetpotato weevil. Crop Sci. 21:499-503.

Kempthorne, 0. 1957. An introduction to genetic statistics. Iowa State University Press, Ames.

Mullen, M.A., A. Jones, D.R. Patterson, and T.E. Boswell. 1985. Resistance in sweetpotato to the sweetpotato weevil. J. Entomol. Sci. 20:345350 . 